\title{
Desain Water Quality Control pada Otomatisasi Kincir Air dan Penggantian Air Tambak Udang Menggunakan Software Cx-Programmer yang Terintegrasi dengan Programmable Logic Controller (PLC) CPM1A
}

Rimas Dwi Klarawati ${ }^{*}$, Gurum Ahmad Pauzi and Arif Surtono

Received: 9 Jan., 2020 | Accepted: 11 Feb., 2020 | Published: 17 Aug., 2020 | DOI: 10.22146/jfi.v24i2.53297

\begin{abstract}
Ringkasan
Telah direalisasikan desain Water Quality Control pada Otomatisasi Kincir Air dan Penggantian Air Tambak Udang menggunakan Software $C_{x}$-One yang terintegrasi dengan Programmable Logic Controller (PLC) CPM1A. Penelitian ini dilakukan untuk mengetahui sistem otomatisasi water Quality Control yang mengoperasikan relay output/aktuator yaitu pompa dan kincir. Sensor input (Dissolved Oxygen (DO), Salinitas, pH dan suhu) dari pembacaan sensor diubah ke dalam bentuk relay, sehingga yang diterima PLC berupa nilai 0 dan 1 . Kemudian diproses oleh PLC dan menghasilkan keputusan 0 dan 1 pada relay output. PLC akan menerima sinyal input dan mengendalikan instrumentasi output serta melaksanakan tugas sesuai dengan perintah program yang dibuat. Apabila nilai input mencapai referensi yang telah diberikan, maka PLC akan mengeksekusi program mengaktifkan relay output (pompa dan kincir). Hasil penelitian diperoleh bahwa nilai Salinitas, pH dan suhu dalam keadaan normal sehingga aktuator pompa dalam keadaan OFF. Sedangkan pada nilai sensor input Dissolved Oxygen (DO) dalam keadaan $O N$ ketika nilai Dissolved Oxygen $<4$ ppm yaitu 3.39 ppm - 3.93 ppm sehingga aktuator kincir bermode $O N$.
\end{abstract}

Kata Kunci : PLC; relay output; Sensor Input; Software CX-One; Water Quality Control

\begin{abstract}
The water quality control design has been realized in the automation of waterwheel and shrimp pond water replacement using the $\mathrm{Cx}_{\mathrm{X}}$-Programmer software on integrated by Programmable Logic Controller (PLC) CPM1A. This research was conducted to determine the water quality control automation system that operates the output relay / actuator, namely pumps and wheels. Input Sensor (Dissolved Oxygen (DO), Salinity, pH and temperature) of the sensor readings is converted into a relay, so that the PLC receives a value of 0 and 1 . Then it is processed by the PLC and produces 0 and 1 decisions on the relay output. The PLC will receive the input signal and control the output instrumentation and carry out the tasks in accordance with the program instructions made. If the input value reaches the given reference, the PLC will execute the program activating the relay output (pump and waterheel). The results obtained that the value of Salinity, $\mathrm{pH}$ and temperature are normal so that the pump actuator is OFF. Whereas the Dissolved Oxygen (DO) input sensor value is ON when the Dissolved Oxygen value $<4 \mathrm{ppm}$ is $3.39 \mathrm{ppm}-3.93 \mathrm{ppm}$ so that the pinwheel actuator is ON.
\end{abstract}

Keywords: CX-One Software; Input sensor; PLC; relay output; Water Quality Control

${ }^{*}$ Correspondence: rimasdwi12@gmail.com

Departemen Fisika, Fakultas Matematika dan Ilmu Pengetahuan,

Universitas Lampung, 35141, Bandar Lampung, Indonesia
Full list of author information is available at the end of the article

${ }^{\dagger}$ Equal contributor 


\section{PENDAHULUAN}

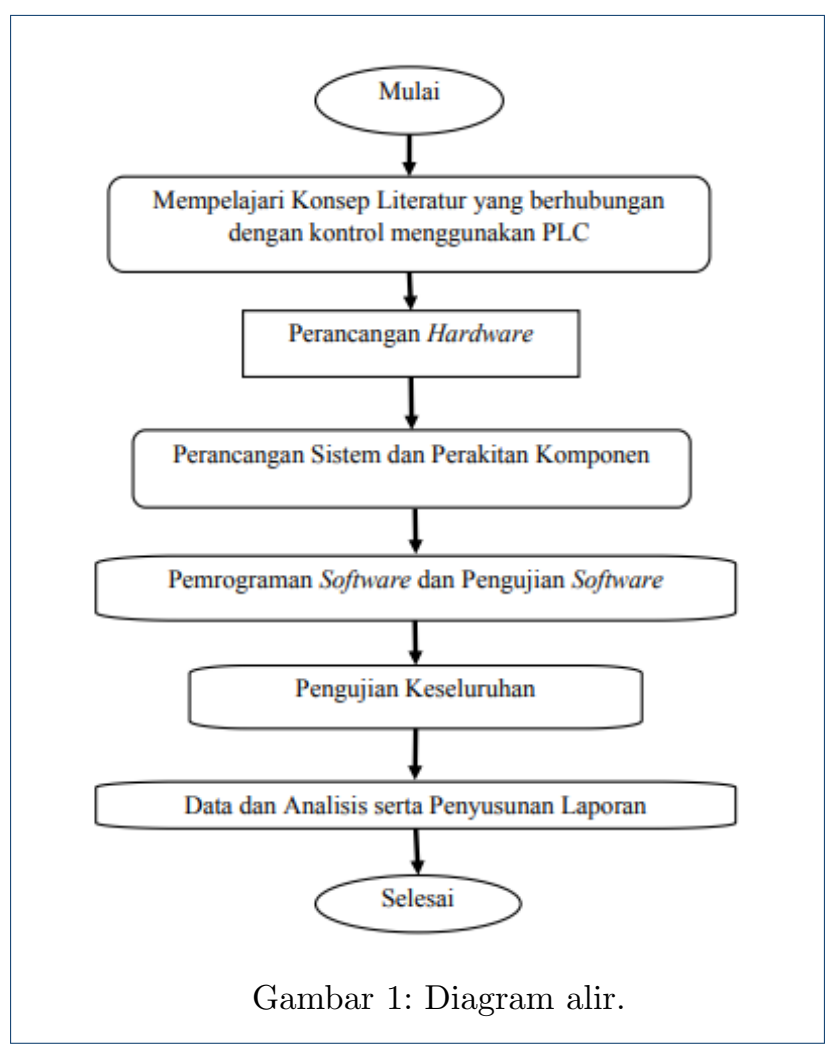

Udang putih (Litopenaeus Vannamei) mulai masuk dan dikenalkan di Indonesia pada tahun 2001 melalui SK Menteri Kelautan dan Perikanan RI. No. 41/2001 sebagai upaya meningkatkan produksi udang Indonesia menggantikan udang windu (Penaeus monodon) yang telah mengalami penurunan produksi [1].

Udang putih adalah jenis udang-udangan (krustasea) yang memiliki tingkat panen tertinggi di dunia dengan total produksi 3.879.786 metrik ton (MT), hampir setengah dari krustasea (7.351.350 metrik ton), ini menunjukkan bahwa udang putih adalah salah satu industri akuakultur yang paling penting [2]. Udang Vaname dianggap sebagai salah satu spesies yang dapat dikembangkan untuk meningkatkan produksi udang nasional, karena memiliki produktivitas dan tingkat kelangsungan hidup tinggi dan periode pertumbuhan lebih cepat (3 bulan) [3]. Lebih tahan terhadap penyakit dibandingkan dengan spesies lain dan toleransi salinitas yang lebih besar [4].

Meskipun mempunyai banyak keunggulan, permasalahan utama yang sering ditemukan dalam kegagalan produksi udang putih adalah buruknya kualitas air selama masa pemeliharaan [5] yang membawa dampak buruh pada kualitas air karena



kotoran, pakan yang tidak dimakan dan masalah organik di lingkungan tambak [6]. Untuk menunjang kinerja pertumbuhan udang, parameter kualitas air diukur setiap hari untuk suhu air, $\mathrm{pH}$, salinitas, kekeruhan dan oksigen terlarut dengan kualias air yang normal yaitu suhu $29^{\circ} \mathrm{C}-34^{\circ} \mathrm{C}, \mathrm{pH}$ 7.6-8.6, salinitas 13-22 ppt, oksigen terlarut 2.6-6.1 mg/L, dan kedalaman air sekitar 100-130 cm [7].

Menjaga kualitas air tambak perlu adanya pengelolaan air yang baik, yaitu dengan cara melakukan penggantian air dan aerasi untuk membantu menyuplai oksigen terlarut [8]. Pada proses penggantian air dan pengoperasian kincir, para petani tambak saat ini masih melakukan dengan cara yang manual. Hal tersebut tentu saja kurang efektif dalam menjaga nilai parameter kualitas air, sehingga perlu dilakukan sistem otomatisasi.

Pada penelitian ini, telah dirancang sistem otomatisasi agar memudahkan petani tambak dalam pengendalian kincir dan penggantian air berdasarkan nilai salinitas dan kadar oksigen terlarut. Salah satunya ialah dengan adanya sistem otomatisasi alat elektronika digital, yaitu menggunakan Programmable Logic Controller (PLC). PLC ialah perangkat logika yang dapat diprogram untuk menyimpan instruksi-instruksi seperti logika, perwaktuan, pencacahan dan aritmatika [9]. PLC dirancang untuk menggantikan sistem logika relay dan memiliki kemampuan untuk mengatur input/output [10]. PLC yang digunakan peneliti ialah jenis PLC CPM1A. Perangkat PLC CPM1A dibuat untuk memproses sistem otomatisasi pada tambak, PLC menerima sinyal input dan mengendalikan instrumentasi output serta melaksanakan tugas sesuai dengan perintah program yang dibuat. Sistem otomatisasi yang dibuat mampu merespon perubahan nilai parameter yang diukur dan dapat menjadi solusi untuk memudahkan petani tambak dalam pengendalian penggantian 


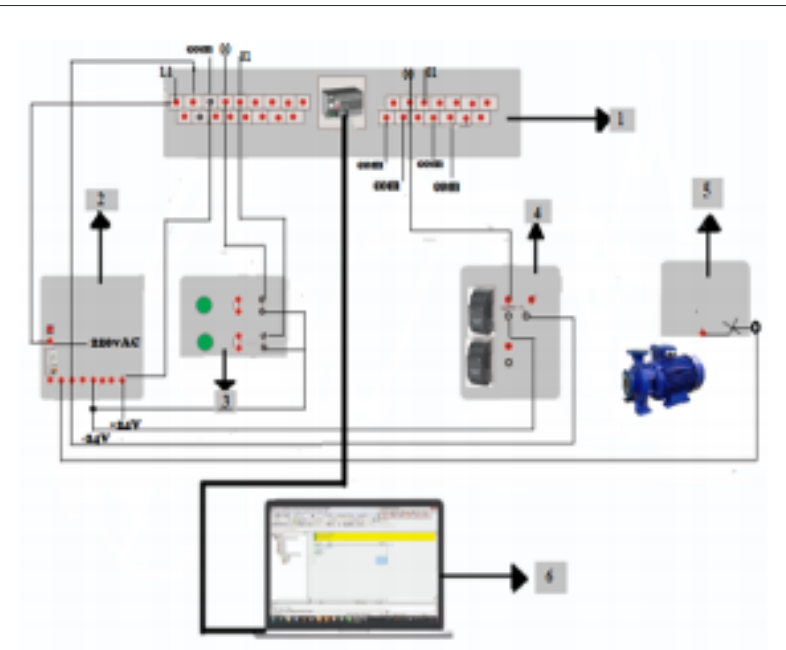

Gambar 3: Desain Water Quality Control 1). Komponen Input dan Output PLC, 2). Power Supply, 3). Relay sensor input, 4). Relay sensor output, 5). Aktuator (kincir dan pompa), 6) Personal Computer (PC).

air serta penghidupan kincir dari manual menjadi otomatis.

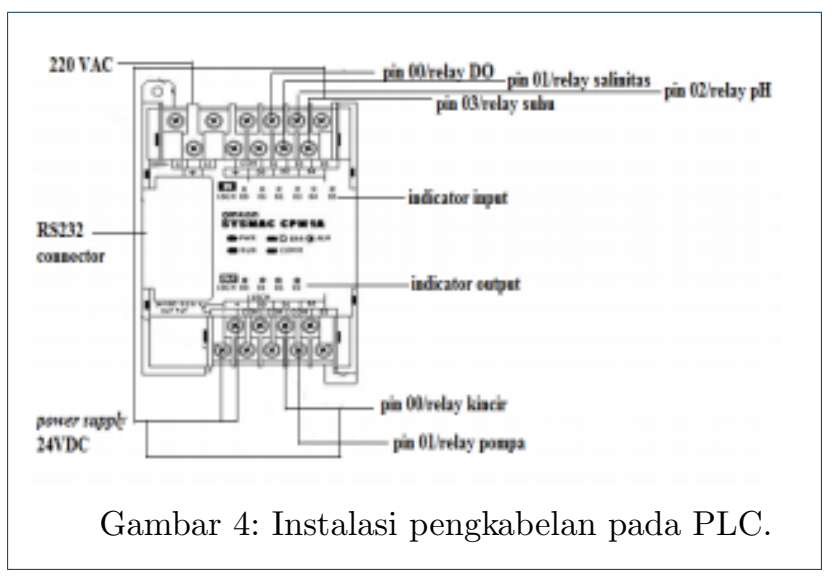

\section{METODE PENELITIAN}

Penelitian ini dilakukan untuk mengetahui desain dan realisasi sistem otomatisasi water quality control yang menggunakan PLC CPM1A untuk menjalankan pergantian air serta penghidupan kincir serta mengetahui instrumentasi input dan output untuk mengecek kualitas air tambak agar sesuai dengan kondisi yang terintegrasi dengan PLC CPM1A. Tahapan tersebut lebih rinci dapat dilihat pada diagram alir Gambar 1.

Langkah pertama: Perancangan perangkat keras (Hardware). Hardware yang dirancang terdiri dari rangkaian elektronika dan instrumen proses. Rangkaian elektronika yang dirancang ialah rangkaian sensor untuk masukan, serta peralatan listrik seperti tombol. Perancangan perangkat keras pada sistem otomatis dihubungkan dengan PLC CPM1A diteruskan ke relay. Blok diagram tersebut dapat dilihat pada Gambar 1.

Pada Gambar 2 dapat dijelaskan bahwa masukan input dari pembacaan sensor diubah ke dalam yang hasilnya berupa relay sehingga yang diterima PLC berupa nilai 0 dan 1 . Kemudian diproses oleh PLC dan menghasilkan keputusan 0 dan 1 yang menghasilkan keluaran berupa relay. Apabila inputan mencapai referensi yang telah diberikan, maka PLC akan mengeksekusi program yaitu mengaktifkan pompa pengisian atau pengosongan air serta peghidupan kincir.

Mendesain Water Quality Control pada otomatisasi kincir air dan penggantian air tambak udang menggunakan PLC Omron CPM1A. Seperti pada Gambar 3.

Langkah Kedua: Perancangan perangkat lunak (software). Setelah perangkat keras dirancang, maka langkah selanjutnya adalah perancangan perangkat lunak. Perangkat lunak ini berfungsi untuk mengatur kinerja keseluruhan dari sistem yang terdiri dari beberapa perangkat keras sehingga sistem ini dapat bekerja dengan baik. Perancangan ini dimulai dengan pembuatan ladder diagram PLC dengan menggunakan software $C X$-Programmer versi 9.5.

\section{HASIL DAN PEMBAHASAN}

\section{Perancangan perangkat keras/Hardware}

Instalasi pengkabelan pada PLC dapat dilihat pada Gambar 4. Instalasi pengkabelan pada PLC yang kemudian disusun menjadi rancangan perangkat keras dengan masing-masing PIN yang sudah terhubung seperti pada Gambar 5. Pada Gambar 4 dan Gambar 5 dapat dijelaskan bahwa masing-masing PIN COM input dan ouput PLC dihubungkan menjadi satu yang kemudian disambungkan ke power supply bertegangan +24 VDC. Relay sensor input dihubungkan ke +24 VDC serta dihubungkan kembali ke PIN input PLC 00 dan 01 sebagai referensi untuk menghidupkan relay PIN output 00 dan 01 yaitu pompa dan kincir. Relay Output yang terhubung pada kincir juga dihubungkan ke 24 VDC dan Personal Computer (PC) yang berfungsi sebagai sarana untuk Upload dan Download program ke PLC.

Perancangan perangkat lunak/software

Perancangan software ini digunakan untuk menggambarkan perangkat logika otomatisasi 
Tabel 1: Hasil Pengamatan Hari Pertama.

\begin{tabular}{|c|c|c|c|c|c|c|}
\hline \multirow[b]{2}{*}{$\begin{array}{l}\text { Waktu Pengukuran } \\
\text { (WIB) }\end{array}$} & \multicolumn{4}{|c|}{ Nilai Sensor } & \multicolumn{2}{|c|}{ Keadaan Aktuator } \\
\hline & $\begin{array}{c}\text { DO } \\
(\mathrm{ppm})\end{array}$ & $\begin{array}{l}\text { Salinitas } \\
\text { (ppt) }\end{array}$ & $\mathrm{PH}$ & $\begin{array}{l}\text { Suhu } \\
\left({ }^{\circ} \mathrm{C}\right)\end{array}$ & Kincir & Pompa \\
\hline 07.30 & 4.86 & 21 & 7.01 & 27.18 & OFF & OFF \\
\hline 12.30 & 3.89 & 21 & 7.20 & 27.18 & ON & OFF \\
\hline 15.30 & 3.36 & 21 & 7.99 & 27.11 & ON & OFF \\
\hline
\end{tabular}

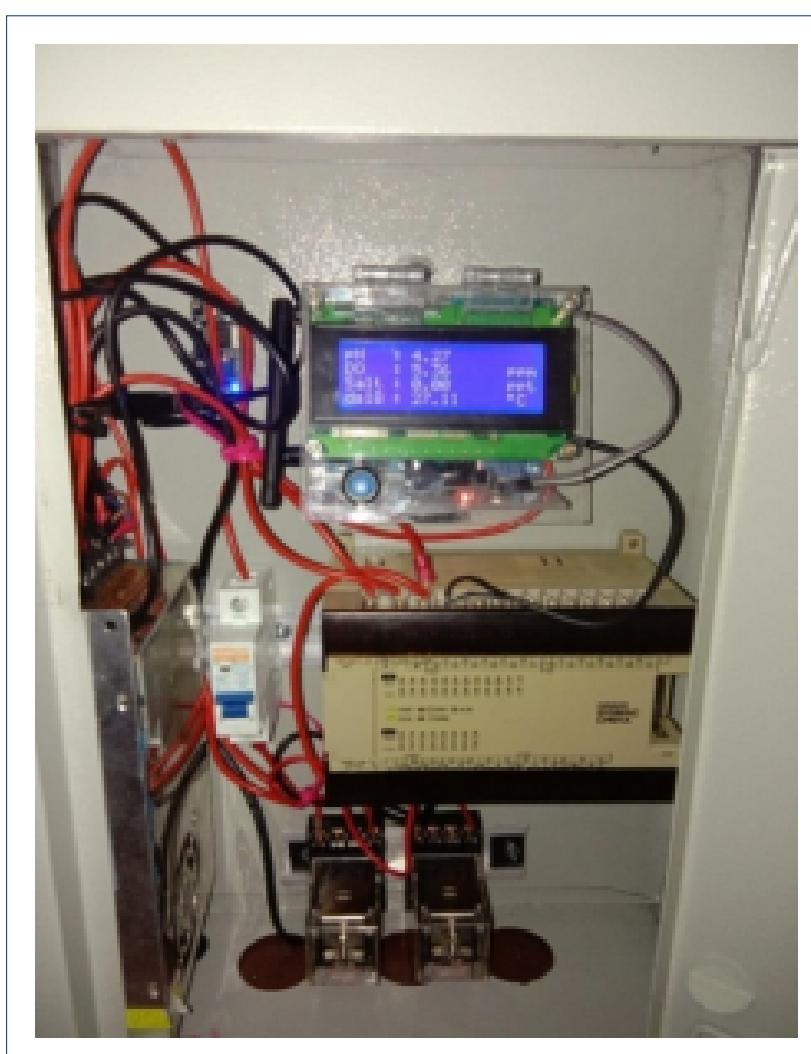

Gambar 5: Rancangan Perangkat keras dengan pin yang terhubung pada PLC.

kincir air dan penggantian air tambak udang yang disesuaikan seperti kondisi yang sebenarnya. Pada proses pembuatan program PLC hal pertama yang harus dilakukan ialah menentukan daftar input dan output, Perintah-perintah ini digunakan sebagai operasi manual yang didesain menjadi sebuah rangkaian menggunakan ladder diagram dalam komputer, seperti pada Gambar 6.

Ladder diagram tersebut memiliki 3 network. Masing-masing network mempunyai instruksi-instruksi yang berbeda. Network 1 untuk pengendalian Kincir dari relay Dissolved Oxygen. Instruksi Ladder diagram input aktif dalam keadaan normally open. Input pada sistem ini yaitu relay pada alamat 0.00 mengaktifkan output berupa instruksi OUT untuk menyalakan pompa pada alamat 10.00. Network 2 terdiri dari instruksi Ladder diagram untuk

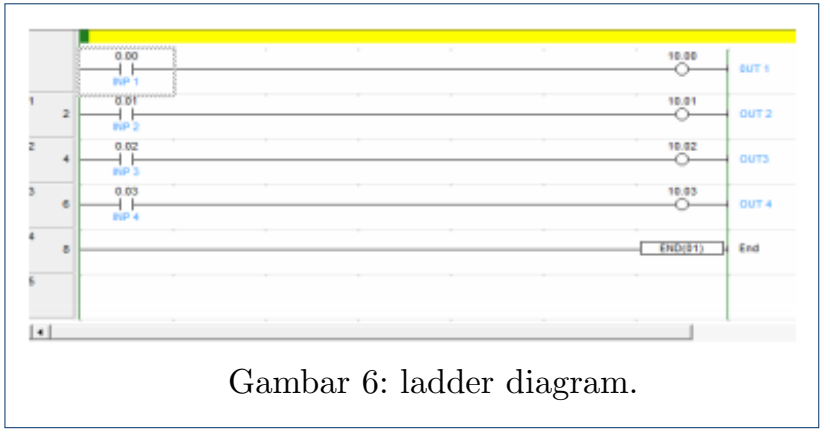

pengendalian pompa, instruksi Ladder diagram input aktif dalam keadaan normally open. Input pada sistem ini yaitu relay pada alamat 0.01 mengaktifkan output berupa instruksi OUT untuk menyalakan kincir pada alamat 10.01. Intruksi $E N D$ pada program digunakan untuk mengakhiri program agar program dapat dijalankan. Sebelum ladder diagram yang buat ditransfer ke dalam perangkat PLC Omron Sysmac CPM1A, langkah pertama yang harus dilakukan adalah melakukan compile program. Tujuannya adalah untuk melihat program yang dibuat terdapat error atau tidak. Jika tidak ditemukan error maka program dapat ditransfer ke dalam PLC. Langkah pengujian program dapat dilihat pada Gambar 7 . Pada pengujian proram ladder diagram hanya perlu

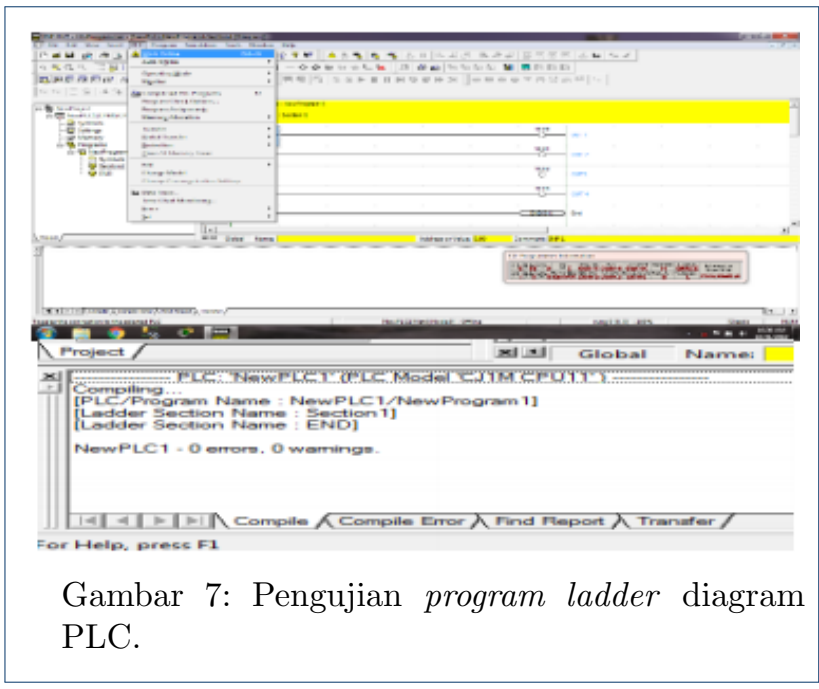

mengklik tombol work online simulator pada toolbar, 
kemudian PLC akan meng-compile dengan memberi informasi error atau tidak.

\section{Proses Transfer Ladder Diagram dari PC ke PLC Omron CPM1A}

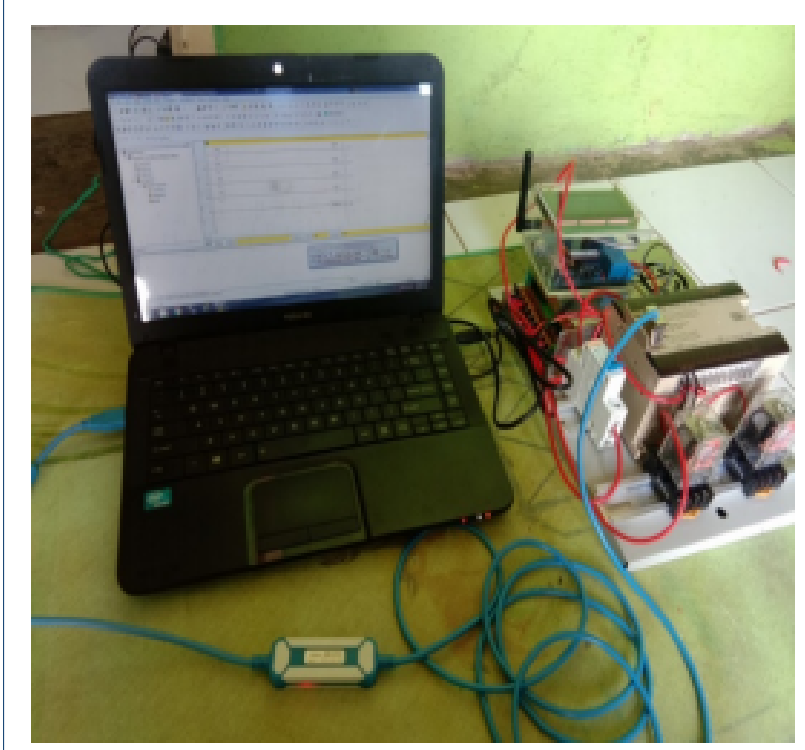

Gambar 8: Proses transfer ladder diagram dari PC ke PLC omron CPM1A.

Langkah terakhir yaitu mentransfer program dengan cara pilih project di menu toolbar, klik menu PLC kemudian pilih transfer dan klik transfer to PLC. Jika PC dan PLC terhubung maka status PLC connected tunggu hingga proses transfer selesai di tandai dengan dengan pemberitahuan download succsessfull. Download program succssesfull artinya program terinstal pada PLC dan alat siap dijalankan.

\section{Rangkaian keseluruhan Desain Water Quality Control}

Sensor input (1) akan mengukur nilai variabel (DO, Salinitas, $\mathrm{Ph}$ dan $\mathrm{Suhu}$ ) secara otomatis pada media plant (2) berdasarkan waktu yang telah ditentukan, yaitu pukul 07.00 WIB 12.00 WIB dan 15.00 WIB. Nilai DO, Salinitas, $\mathrm{Ph}$ dan Suhu akan memberi keputusan pada relay input (3) setelah setengah jam kemudian, yaitu pukul 07.30 WIB 12.30 WIB dan 15.30 WIB. PLC akan mengambil keputusan dengan menghidupkan aktuator kincir dan pompa (5) apabila telah mencapai ambang batas yang ditentukan (DO $\leq 4 \mathrm{ppm}$, salinitas $\leq 10 \mathrm{ppt}, \mathrm{pH} \leq 6$ dan suhu $>35^{\circ} \mathrm{C}$ ). PLC akan mengeksekusi program dengan mengaktifkan relay output (5)yaitu pompa dan kincir berdasarkan ladder diagram yang telah dibuat. Kincir dan pompa akan hidup secara otomatis sesuai dengan referensi yang telah ditetapkan. Tabel 1 merupakan

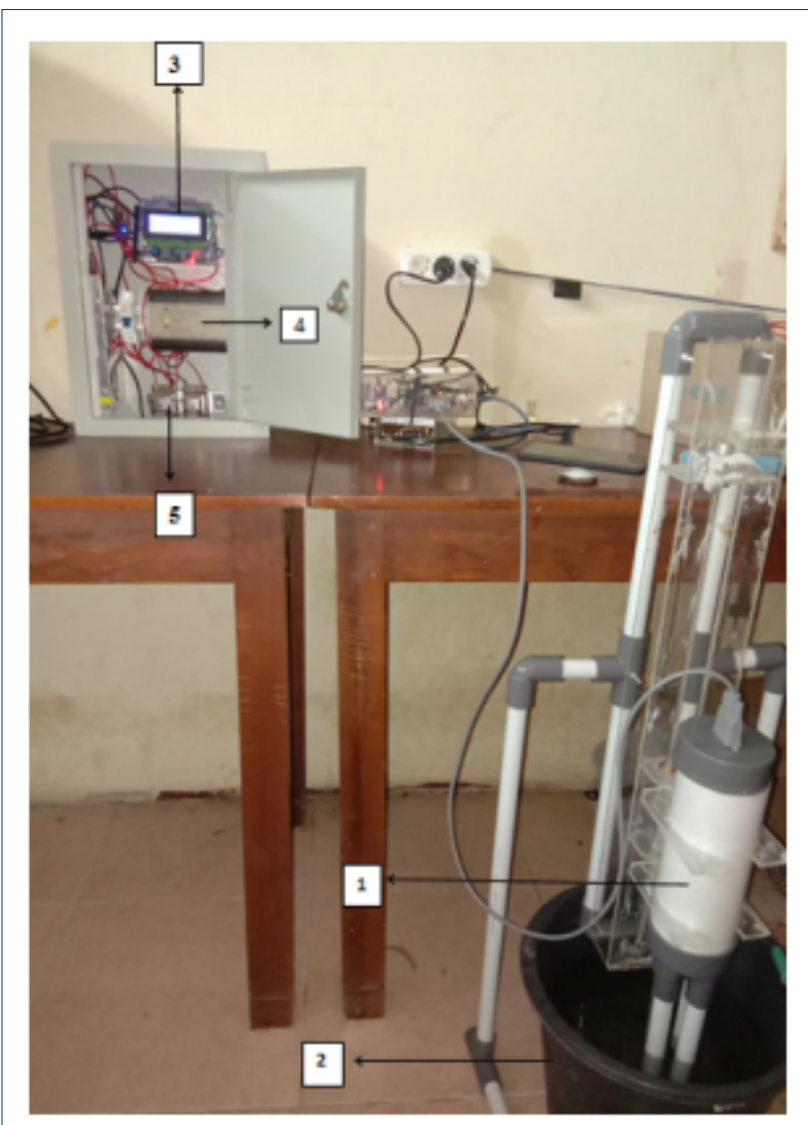

Gambar 9: Rangkain keseluruhan Desain Water Quality Control 1). Sensor Input (DO, Salinitas, $\mathrm{pH}$ dan Suhu), 2). Media plant, 3). Relay sensor input, 4). PLC, 5). Relay output (aktuator kincir dan pompa).

pengujian keadaan pompa dan kincir terhadap sensor masukan pada hari pertama.

Hasil pengamatan hari pertama dengan pengambilan keputusan pukul 07.30 WIB nilai DO, salinitas, PH dan Suhu yaitu $4.86 \mathrm{ppm}, 21 \mathrm{ppt}$, 7.01 dan $27.18^{\circ} \mathrm{C}$ dalam keadaan normal, sehingga keadaan aktuator tetap OFF. Pada pengukuran berikutnya yaitu pengambilan keputusan pukul 12.30 WIB dan 15.30 WIB terlihat bahwa nilai DO yang rendah atau < $4 \mathrm{ppm}$ yaitu $3.89 \mathrm{ppm}$ dan 3.36 ppm, sehingga memberikan inputan kepada PLC dan mengeksekusi program keadaan aktuator pada kincir menyala atau $O N$.

Hasil pengamatan hari kedua dengan pengambilan keputusan pukul 07.30 WIB, 12.30 WIB dan 15.30 WIB menghasilkan nilai DO yang rendah yaitu 3.47 ppm, $3.39 \mathrm{ppm}$ dan $3.86 \mathrm{ppm}$. Sehingga aktuator pada kincir dalam keadaan menyala atau ON, sesuai dengan referensi yang didapat bahwa jika DO berkisar $<4$ ppm maka kincir harus dihidupkan sedangkan untuk 
Tabel 2: Hasil Pengamatan Hari Kedua.

\begin{tabular}{|c|c|c|c|c|c|c|}
\hline $\begin{array}{c}\text { Waktu Pengukuran } \\
\text { (WIB) }\end{array}$ & \multicolumn{4}{|c|}{ Nilai Sensor } & \multicolumn{2}{|c|}{ Keadaan Aktuator } \\
& $\begin{array}{c}\text { Dolinitas } \\
(\mathrm{ppm})\end{array}$ & $\begin{array}{c}\text { Salin } \\
(\mathrm{ppt})\end{array}$ & $\mathrm{PH}$ & $\begin{array}{c}\text { Suhu } \\
\left({ }^{\circ} \mathrm{C}\right)\end{array}$ & Kincir & Pompa \\
\hline 07.30 & 3.47 & 21 & 8.19 & 27.11 & ON & OFF \\
\hline 12.30 & 3.39 & 21 & 6.90 & 27.05 & ON & OFF \\
\hline 15.30 & 3.86 & 21 & 7.18 & 27.36 & ON & OFF \\
\hline
\end{tabular}

Tabel 3: Hasil Pengamatan Hari Ketiga.

\begin{tabular}{|c|c|c|c|c|c|c|}
\hline $\begin{array}{c}\text { Waktu Pengukuran } \\
\text { (WIB) }\end{array}$ & \multicolumn{4}{|c|}{ Nilai Sensor } & \multicolumn{2}{|c|}{ Keadaan Aktuator } \\
& $\begin{array}{c}\text { Solinitas } \\
(\mathrm{ppm})\end{array}$ & $\mathrm{PH}$ & $\begin{array}{c}\text { Suhu } \\
(\mathrm{ppt})\end{array}$ & Kincir & Pompa \\
\hline 07.30 & 5.32 & 21 & 6.98 & 27.18 & OFF & OFF \\
\hline 12.30 & 4.04 & 21 & 6.94 & 27.05 & OFF & OFF \\
\hline 15.30 & 3.07 & 21 & 7.18 & 27.36 & ON & OFF \\
\hline
\end{tabular}

nilai salinitas, PH dan Suhu masih dalam keadaan normal.

Hasil pengamatan pada hari ketiga dengan pengambilan keputusan pukul 07.30 WIB nilai DO, salinitas, PH dan Suhu yaitu 5.32 ppm, 20 ppt, 6.98 dan $27.18{ }^{\circ} \mathrm{C}$ dalam keadaan normal, sehingga keadaan aktuator tetap OFF. Pada pengukuran berikutnya yaitu pengambilan keputusan pukul 12.30 WIB dengan nilai DO yang tidak stabil dari pengambilan keputusan pertama yang menurun pada kisaran 4.04 sehingga kincir masih tetap dalam keadaan OFF. Sedangkan pada pukul 15.30 WIB terlihat bahwa nilai DO yang rendah atau $<4 \mathrm{ppm}$ yaitu 3.07 ppm sehingga memberikan inputan kepada PLC dan mengeksekusi program keadaan aktuator pada kincir menyala atau $O N$.

\section{KESIMPULAN}

Berdasarkan hasil penelitian, analisis dan pembahasan diperoleh bahwa Sistem Water Quality Control pada otomatisasi kincir air dan penggantian air tambak udang menggunakan PLC Omron CPM1A berjalan dengan baik sesuai yang diharapkan. Apabila nilai sensor masukan sudah melebihi ambang batas maka keadaan kincir dan Pompa bermode ON. Program Ladder Diagram yang di Download ke PLC sesuai dengan apa yang diinginkan. PLC akan mengeksekusi program dalam keadaan ON yang memberikan nilai 1 pada relay output ketika nilai Dissolved Oxygen $<4$ ppm sehingga aktuator kincir bermode $O N$.

\section{PENULIS}

1 Rimas Dwi Klarawati

Dari :

(1) Departemen Fisika, Fakultas Matematika dan Ilmu Pengetahuan, Universitas Lampung
2 Gurum Ahmad Pauzi Dari :

(1) Departemen Fisika, Fakultas Matematika dan Ilmu Pengetahuan, Universitas Lampung

3 Arif Surtono

Dari :

(1) Departemen Fisika, Fakultas Matematika dan Ilmu Pengetahuan, Universitas Lampung

Pustaka

1. Purnamasari I, Purnama D, Utami MAF. Pertumbuhan Udang Vaname (Litopenaeus Vannamei) di Tambak Intensif. Jurnal Enggano. 2017;2(1)

2. Meng N, Ju-lin Y, Mei L, Zhi-min G. Assessment of water quality and phytoplankton community of Limpenaeus vannamei pond in intertidal zone of Hangzhou. Aquaculture Reports. 2018;

3. Ruswahyuni, Hartoko A, Rudiyanti S. Aplication Of Chitosan For Water Quality And Macrobenthic Fauna Rehabilitation In Vannamei Shrimps (Litopenaeus Vannamei) Ponds, North Coast Of Semarang, Central Java - Indonesia. Journal of Coastal Development. 2010;14(1).

4. Wyban, J ASweeney JA. Intensive Shrimp Production Technology. The Oceanic Institute. 1991;p. 163.

5. Arsad S, Afandy A, Purwadhi AP, V BM, Saputra DK, Buwono NR. Studi Kegiatan Budidaya Pembesaran Udang Vaname (Litopenaeus Vannamei) Dengan Penerapan Sistem Pemeliharaan Berbeda. Jurnal Ilmiah Perikanan dan Kelautan. 2017;9(1).

6. Kumar VS, Pandey PK, Anand T, Bhuvaneswari R, Kumar S. Effect of periphyton (aquamat) on water quality, nitrogen budget, microbial ecology, and growth parameters of Litopenaeusvannamei in a semi-intensive culture system. Aquaculture. 2017;479:240-249.

7. Junda M. Development of Intensive Shrimp Farming, Litopenaeus vannamei In Land-Based Ponds: Production and Management. IOP ConfSeries: Journal of Physics. 2018;.

8. Fuady MF, Haeruddin, Nitisupardjo M. Pengaruh Pengelolaan Kualitas Air Terhadap Tingkat Kelulushidupan dan Laju Pertumbuhan Udang Vaname (Litopenaeus Vannamei) di PT. Indokor Bangun Desa, Yogyakarta. Diponegoro Journal of Maquares. 2013;2(4).

9. Patel R, Shewale AN, Patil CS. Automated Cooking Machine Using Programmable Logic Controller (PLC). International Journal of Computer Science Trends and Technology (IJCST). 2016;4(4).

10. Lashen M. Different Applications Of Programmablelogic Controller (PLC). International Journal of Computer Science, Engineering and Information Technology (IJCSEIT). 2014;4(1). 